\title{
Length-dependent changes in contractile dynamics are blunted due to cardiac myosin binding protein- $\mathrm{C}$ ablation
}

\author{
Ranganath Mamidi, Kenneth S. Gresham and Julian E. Stelzer* \\ Department of Physiology and Biophysics, School of Medicine, Case Western Reserve University, Cleveland, OH, USA
}

\section{Edited by:}

Julien Ochala, King's College

London, UK

Reviewed by:

Corrado Poggesi, University of

Florence, Italy

Brett Colson, University of

Minnesota, USA

*Correspondence:

Julian E. Stelzer, Department of Physiology and Biophysics, School of Medicine, Case Western Reserve

University, 2109 Adelbert Rd,

Robbins E522, Cleveland, $\mathrm{OH}$

44106, USA

e-mail: julian.stelzer@case.edu
Enhanced cardiac contractile function with increased sarcomere length (SL) is, in part, mediated by a decrease in the radial distance between myosin heads and actin. The radial disposition of myosin heads relative to actin is modulated by cardiac myosin binding protein-C (cMyBP-C), suggesting that $\mathrm{CMyBP}-\mathrm{C}$ contributes to the length-dependent activation (LDA) in the myocardium. However, the precise roles of cMyBP-C in modulating cardiac LDA are unclear. To determine the impact of CMyBP-C on LDA, we measured isometric force, myofilament $\mathrm{Ca}^{2+}$-sensitivity $\left(\mathrm{pCa}_{50}\right)$ and length-dependent changes in kinetic parameters of cross-bridge $(\mathrm{XB})$ relaxation $\left(k_{\text {rel }}\right)$, and recruitment $\left(k_{\mathrm{df}}\right)$ due to rapid stretch, as well as the rate of force redevelopment $\left(k_{\mathrm{tr}}\right)$ in response to a large slack-restretch maneuver in skinned ventricular multicellular preparations isolated from the hearts of wild-type (WT) and cMyBP-C knockout (KO) mice, at SL's $1.9 \mu \mathrm{m}$ or $2.1 \mu \mathrm{m}$. Our results show that maximal force was not significantly different between $\mathrm{KO}$ and WT preparations but length-dependent increase in $\mathrm{pCa}_{50}$ was attenuated in the KO preparations. pCa50 was not significantly different between WT and KO preparations at long SL (5.82 \pm 0.02 in WT vs. $5.87 \pm 0.02$ in $\mathrm{KO})$, whereas pCa50 was significantly different between WT and KO preparations at short SL (5.71 \pm 0.02 in WT vs. $5.80 \pm$ 0.01 in $\mathrm{KO} ; p<0.05)$. The $k_{\mathrm{tr}}$, measured at half-maximal $\mathrm{Ca}^{2+}$-activation, was significantly accelerated at short SL in WT preparations $\left(8.74 \pm 0.56 \mathrm{~s}^{-1}\right.$ at $1.9 \mu \mathrm{m}$ vs. $5.71 \pm 0.40$ $\mathrm{s}^{-1}$ at $\left.2.1 \mu \mathrm{m}, p<0.05\right)$. Furthermore, $k_{\mathrm{rel}}$ and $k_{\mathrm{df}}$ were accelerated by $32 \%$ and $50 \%$, respectively at short SL in WT preparations. In contrast, $k_{\mathrm{tr}}$ was not altered by changes in $\mathrm{SL}$ in $\mathrm{KO}$ preparations $\left(8.03 \pm 0.54 \mathrm{~s}^{-1}\right.$ at $1.9 \mu \mathrm{m}$ vs. $8.90 \pm 0.37 \mathrm{~s}^{-1}$ at $\left.2.1 \mu \mathrm{m}\right)$. Similarly, $\mathrm{KO}$ preparations did not exhibit length-dependent changes in $k_{\mathrm{rel}}$ and $k_{\mathrm{df}}$. Collectively, our data implicate CMyBP-C as an important regulator of LDA via its impact on dynamic XB behavior due to changes in SL.

Keywords: $\mathrm{cMyBP}-\mathrm{C}$, length-dependent activation, sarcomere length, myofilament function, cross-bridge kinetics

\section{INTRODUCTION}

Length-dependent activation (LDA) is the mechanism by which force production in the heart becomes more sensitive to $\mathrm{Ca}^{2+}$ as the sarcomere length (SL) is increased (Allen and Kentish, 1985). Although it is well recognized that LDA underlies the Frank-Starling's Law of the heart, the cellular and molecular mechanisms that modulate this process are still poorly understood mainly because LDA involves a dynamic and complex interplay between a multitude of thick- and thin-filament-based mechanisms (De Tombe et al., 2010). The thick-filament-based mechanisms involve augmentation of strong crossbridge (XB) formation followed by enhancement in the myofilament $\mathrm{Ca}^{2+}$ sensitivity upon a reduction in the myofilament lattice spacing and the radial distance between the thick and thin filaments at long SL (Fuchs and Smith, 2001). The strongly-bound XBs then cooperatively recruit additional near-neighbor XBs into the force-bearing state (Gordon et al., 2000; Regnier et al., 2004). The thin-filament-based mechanisms involve an increased affinity of troponin $\mathrm{C}(\mathrm{TnC})$ to $\mathrm{Ca}^{2+}$ when the neighboring $\mathrm{TnC}$ sites are bound with $\mathrm{Ca}^{2+}$ and the increased affinity of $\mathrm{TnC}$ to $\mathrm{Ca}^{2+}$ is also a result of a positive feedback effect of the stronglybound XBs (Hannon et al., 1992; Moss et al., 2004; Li et al., 2014). Furthermore, the cooperative effect between neighboring troponin-tropomyosin ( Tn-Tm) complexes also impacts the $\mathrm{Ca}^{2+}$ binding properties of the thin-filament (Butters et al., 1997; Farman et al., 2010) and thus influence the LDA in cardiac muscle (for details on LDA refer to reviews by Konhilas et al., 2002; Hanft et al., 2008; De Tombe et al., 2010; Campbell, 2011).

Earlier investigations have proposed that LDA in cardiac muscle is influenced by various sarcomeric proteins such as $\mathrm{TnC}$ (Gulati et al., 1991), TnI (Konhilas et al., 2003; Tachampa et al., 2007), TnT (Chandra et al., 2006), myosin heavy chain (Korte and McDonald, 2007), essential light chain (Michael et al., 2013), and titin (Fukuda et al., 2003). In addition to the aforementioned sarcomeric proteins, it is also possible that cardiac myosin binding protein-C (cMyBP-C) may be an important modulator of cardiac LDA because cMyBP-C is uniquely positioned in the sarcomere to interact with both the thick- and thin-filaments (Squire 
et al., 2003; Shaffer et al., 2009; Previs et al., 2012; Sadayappan and De Tombe, 2012; Mun et al., 2014), and has been shown to be important in regulating key aspects of dynamic XB behavior (Stelzer et al., 2006a,b; Coulton and Stelzer, 2012), and providing structural rigidity to the myofilament lattice (Palmer et al., 2011).

Importantly, recent evidence from low-angle X-ray diffraction experiments showed that $\mathrm{CMyBP}-\mathrm{C}$ tethers the myosin $\mathrm{XBs}$ closer to the thick-filament backbone and that ablation of cMyBP-C results in the radial displacement of XBs closer to the thinfilament (Colson et al., 2007). The role of cMyBP-C in LDA is also underscored by the observation that length-dependent increase in myofilament $\mathrm{Ca}^{2+}$ sensitivity was blunted in cardiac preparations from patients with cMyBP-C mutations (Van Dijk et al., 2012; Sequeira et al., 2013). However, the precise roles of cMyBP-C in modulating length-dependent changes in cardiac contractile dynamics are still unknown. Therefore, to determine the impact of cMyBP-C on length-dependent changes in contractile dynamics, we utilized skinned myocardium from a cMyBP-C knock-out (KO) mouse model (Harris et al., 2002), and measured steady-state contractile parameters and we also used stretch activation experiments to measure the kinetic parameters. We measured $\mathrm{Ca}^{2+}$-activated maximal force, myofilament $\mathrm{Ca}^{2+}$ sensitivity $\left(\mathrm{pCa}_{50}\right)$, rate of force redevelopment $\left(k_{\mathrm{tr}}\right)$, rate of $\mathrm{XB}$ relaxation $\left(k_{\mathrm{rel}}\right)$, and rate of $\mathrm{XB}$ recruitment $\left(k_{\mathrm{df}}\right)$ at short $(1.9 \mu \mathrm{m})$ and at long $(2.1 \mu \mathrm{m})$ SL's. Our results show that the length-dependent increase in $\mathrm{pCa}_{50}$ was attenuated in the KO preparations compared to wild-type (WT) preparations. Furthermore, length-dependent changes in dynamic contractile parameters $k_{\mathrm{tr}}, k_{\mathrm{rel}}$, and $k_{\mathrm{df}}$ were blunted in KO preparations compared to WT preparations, indicating that $\mathrm{cMyBP}-\mathrm{C}$ plays a critical role in the myofilament-mediated response in cardiac LDA.

\section{MATERIALS AND METHODS}

\section{ETHICAL APPROVAL AND ANIMAL TREATMENT PROTOCOLS}

This study was performed according to the protocols laid out in the Guide for the Care and Use of Laboratory Animals (NIH Publication No. 85-23, Revised 1996), and was conducted according to the guidelines of the Institutional Animal Care and Use Committee at Case Western Reserve University. Mice aged 3-6 months, of both sexes, and belonging to SV/129 strain were used for the experiments. KO mice used in this study were previously generated and well-characterized (Harris et al., 2002). WT mice expressing normal, full-length $\mathrm{cMyBP}-\mathrm{C}$ in the myocardium were used as controls.

\section{ESTIMATION OF CMYBP-C CONTENT AND PHOSPHORYLATION STATUS OF SARCOMERIC PROTEINS IN WT AND KO HEART SAMPLES}

Cardiac myofibrils were isolated from frozen mouse ventricles on the day of the experiment (Gresham et al., 2014). A piece of the frozen tissue was thawed in a fresh relaxing solution, homogenized, and the myofibrils were then skinned for $15 \mathrm{~min}$ with $1 \%$ Triton X-100 (Cheng et al., 2013). Skinned myofibrils were then resuspended in fresh relaxing solution containing protease and phosphatase inhibitors (PhosSTOP and cOmplete ULTRA Tablets; Roche Applied Science, Indianapolis, IN, USA) and stored on ice. To determine the $\mathrm{cMyBP}-\mathrm{C}$ content and myofilament protein phosphorylation status, ventricular samples were solubilized by adding Laemmli buffer and were heated to $90^{\circ} \mathrm{C}$ for $5 \mathrm{~min}$. For Western blot analysis, $10 \mu \mathrm{g}$ of cardiac myofibrils were electrophoretically separated on $4-20 \%$ Trisglycine gels (Lonza Walkersville Inc., Rockland, ME, USA) at $180 \mathrm{~V}$ for $60 \mathrm{~min}$. Proteins were transferred to PVDF membranes and incubated overnight with a primary antibody that detects cMyBP-C (Santa Cruz Biotechnology, Santa Cruz, CA, USA) as described previously (Cheng et al., 2013). For Pro-Q phosphoprotein analysis, $2.5 \mu \mathrm{g}$ of solubilized cardiac myofibrils were electrophoretically separated at $180 \mathrm{~V}$ for $85 \mathrm{~min}$ then fixed and stained with Pro-Q diamond phosphoprotein stain (Invitrogen, Carlsbad, CA, USA) to assess the phosphorylation status of sarcomeric proteins. After imaging the Pro-Q stained gels, the gels were counterstained with Coomassie blue to determine if there are any changes in the isoform expression of sarcomeric proteins. Densitometric scanning of the stained gels was done using Image J software (U.S. National Institutes of Health, Bethesda, MD, USA) (Gresham et al., 2014).

\section{PREPARATION OF SKINNED VENTRICULAR MULTICELLULAR PREPARATIONS AND $\mathrm{Ca}^{2+}$ SOLUTIONS FOR EXPERIMENTS}

Skinned ventricular multicellular preparations were prepared as described previously (Cheng et al., 2013; Gresham et al., 2014). In brief, ventricular tissue was homogenized in a relaxing solution and skinned for 60 min using 1\% Triton-X 100. Multicellular preparations with dimensions $\sim 100 \mu \mathrm{m}$ in width and $400 \mu \mathrm{m}$ in length were selected for the experiments. The composition of various $\mathrm{Ca}^{2+}$ activation solutions used for the experiments was calculated using a computer program (Fabiato, 1988) and known stability constants (Godt and Lindley, 1982). All solutions contained the following (in mM): $100 \mathrm{~N}, \mathrm{~N}$-bis (2-hydroxyethyl)2-aminoethanesulfonic acid (BES), 15 creatine phosphate, 5 dithiothreitol, 1 free $\mathrm{Mg}^{2+}$, and $4 \mathrm{MgATP}$. The maximal activating solution ( $\mathrm{pCa} 4.5 ; \mathrm{pCa}=-\log \left[\mathrm{Ca}^{2+}\right]_{\text {free }}$ ) also contained 7 EGTA and 7.01 $\mathrm{CaCl}_{2}$; while the relaxing solution ( $\mathrm{pCa} 9.0$ ) contained 7 EGTA and $0.02 \mathrm{CaCl}_{2}$; and the pre-activating solution contained 0.07 EGTA. The $\mathrm{pH}$ of the $\mathrm{Ca}^{2+}$ solutions was set to 7.0 with $\mathrm{KOH}$ and the ionic strength was $180 \mathrm{mM}$. A range of pCa solutions, containing varying amounts of $\left[\mathrm{Ca}^{2+}\right]_{\text {free }}$, were then prepared by mixing appropriate volumes of $\mathrm{pCa} 9.0$ and 4.5 stock solutions and the experiments were performed at $22^{\circ} \mathrm{C}$.

\section{EXPERIMENTAL APPARATUS FOR THE ESTIMATION OF ISOMETRIC FORCE AND FORCE-PCA RELATIONSHIPS}

Detergent-skinned ventricular preparations were held between a motor arm (312C; Aurora Scientific Inc., Aurora, Ontario, Canada) and a force transducer (403A; Aurora Scientific Inc.) as described previously (Merkulov et al., 2012; Cheng et al., 2013). Changes in the motor position and signals from the force transducer were sampled (16-bit resolution, DAP5216a, Microstar Laboratories; Bellevue, WA) at $2.0 \mathrm{kHz}$ using SL control software (Campbell and Moss, 2003). As previously described (Stelzer et al., 2006a,b,c), the experimental set up was positioned on the stage of an inverted microscope (Olympus; Tokyo, Japan) that was fitted with a 40X objective and a closed-circuit television camera (model WV-BL600; Panasonic, Tokyo, Japan). To illuminate the multicellular preparations, we used the light emanating from 
a halogen lamp and the light was passed through a cut-off filter (transmission $>620 \mathrm{~nm}$ ) before reaching the preparation. Bitmap images of the preparations were captured using an AGP 4X/2X graphics card and its associated software (ATI Technologies) to assess the SL of our preparations during the experiment. For all mechanical measurements, SL of the muscle preparations was set to 1.9 or $2.1 \mu \mathrm{m}$ in a relaxing solution and submaximal force (P) developed at each $\mathrm{pCa}$ was normalized to maximal force $\left(\mathrm{P}_{\mathrm{o}}\right.$, at $\mathrm{pCa} 4.5)$ i.e., $\mathrm{P} / \mathrm{P}_{\mathrm{o}}$ to construct the force-pCa relationships (Desjardins et al., 2012; Cheng et al., 2013). SL of the preparations was initially set using a high definition video camera and large video monitor, and was also assessed at the end of experiments to make sure that SL did not deviate from the initial SL following $\mathrm{Ca}^{2+}$-activation. We chose this specific range of SL for our experiments because this range falls within the wellcharacterized working range $(\sim 1.8-2.3 \mu \mathrm{m})$ of the sarcomeres in the heart muscle (Pollack and Huntsman, 1974; Rodriguez et al., 1992; Granzier and Irving, 1995; Hanft et al., 2008). The apparent cooperativity of force development was estimated from the steepness of a Hill plot transformation of the force-pCa relationships. The force-pCa data were fit using the equation $\mathrm{P} / \mathrm{P}_{\mathrm{o}}=$ $\left[\mathrm{Ca}^{2+}\right]^{n H} /\left(k^{n H}+\left[\mathrm{Ca}^{2+}\right]^{n H}\right)$, where $n_{H}$ is the Hill coefficient and $k$ is the pCa required to produce half-maximal activation (i.e., $\mathrm{pCa}_{50}$ ) (Gresham et al., 2014).

\section{MEASUREMENT OF THE RATE OF FORCE REDEVELOPMENT $\left(\boldsymbol{K}_{\boldsymbol{t} r}\right)$}

$k_{\mathrm{tr}}$ was measured at $50 \%$ of maximal activation in WT and $\mathrm{KO}$ muscle preparations to assess the rate of $\mathrm{XB}$ transitions from weak- to strong-binding states (Brenner and Eisenberg, 1986; Campbell, 1997). Measurement of $k_{\mathrm{tr}}$ in $\mathrm{Ca}^{2+}$-activated muscle preparations was performed according to a mechanical slackrestretch protocol described previously (Stelzer et al., 2006b; Chen et al., 2010; Cheng et al., 2013). Skinned muscle preparations were transferred from relaxing ( $\mathrm{pCa} 9.0$ ) to an activating $\mathrm{Ca}^{2+}$ solution (pCa ranging from 6.2 to 4.5 ), and once the muscle preparations attained steady-state isometric force, they were rapidly slackened by $20 \%$ of their original muscle length and were held for $10 \mathrm{~ms}$ using a high-speed length control device (Aurora Scientific Inc.). The slackening was followed by the brief period of unloaded shortening which resulted in a rapid decline in force due to detachment of the strongly-bound XBs. The muscle preparation was then rapidly restretched back to its original length and the time course of force redevelopment was measured. $k_{\mathrm{tr}}$ for each slack-restretch maneuver was estimated by linear transformation of the half-time of force redevelopment, i.e., $k_{\mathrm{tr}}=0.693 / t_{1 / 2}$, as described previously (Chen et al., 2010; Cheng et al., 2013; Gresham et al., 2014).

\section{STRETCH ACTIVATION EXPERIMENTS TO MEASURE DYNAMIC CONTRACTILE PARAMETERS}

Stretch activation experiments were carried out as previously described (Cheng et al., 2013; Gresham et al., 2014), except that in this study a $2 \%$ stretch of initial muscle length perturbation was utilized. Muscle preparations were placed in $\mathrm{pCa}$ solutions that produced submaximal force ( $\sim 50 \%$ of maximal force), and were allowed to develop a steady-state force. Muscle preparations were then rapidly stretched by $2 \%$ of their initial muscle length and were held at the increased length for $5 \mathrm{~s}$ before being returned back to their initial muscle length. The characteristic features of the stretch activation response in cardiac muscle have been described previously (Stelzer et al., 2006d; Ford et al., 2010), and the stretch activation parameters measured are presented in Figure 1. In brief, a sudden 2\% stretch of muscle length elicits an instantaneous rise in force (P1) in the muscle preparation, which is due to the strain of elastic elements within the strongly-bound XBs (Phase 1). The force then rapidly declines because the strained XBs rapidly detach (Phase 2) and equilibrate into a non-force producing state, with a characteristic rate constant $k_{\text {rel }}$. Following this phase of rapid decline, force development occurs gradually (Phase 3 ), with a characteristic rate constant $k_{\mathrm{df}}$, which is a result of length-induced recruitment of new XBs into the force-bearing state (Stelzer et al., 2006d; Gresham et al., 2014). Stretch activation amplitudes were normalized to prestretch $\mathrm{Ca}^{2+}$-activated force and were measured as described previously (Desjardins et al., 2012; Gresham et al., 2014). $k_{\text {rel }}$ and $k_{\mathrm{df}}$ were estimated using a linear transformation of the half time of force decay and force redevelopment.

\section{DATA ANALYSIS}

Data were analyzed using Two-Way analysis of variance (ANOVA). One factor in this analysis was cMyBP-C variant (WT or $\mathrm{KO})$, and the second was SL (1.9 or $2.1 \mu \mathrm{m})$. Therefore, we used Two-Way ANOVA to test the hypothesis that the effect of the $\mathrm{SL}$ on a given contractile parameter depended on the cMyBP-C

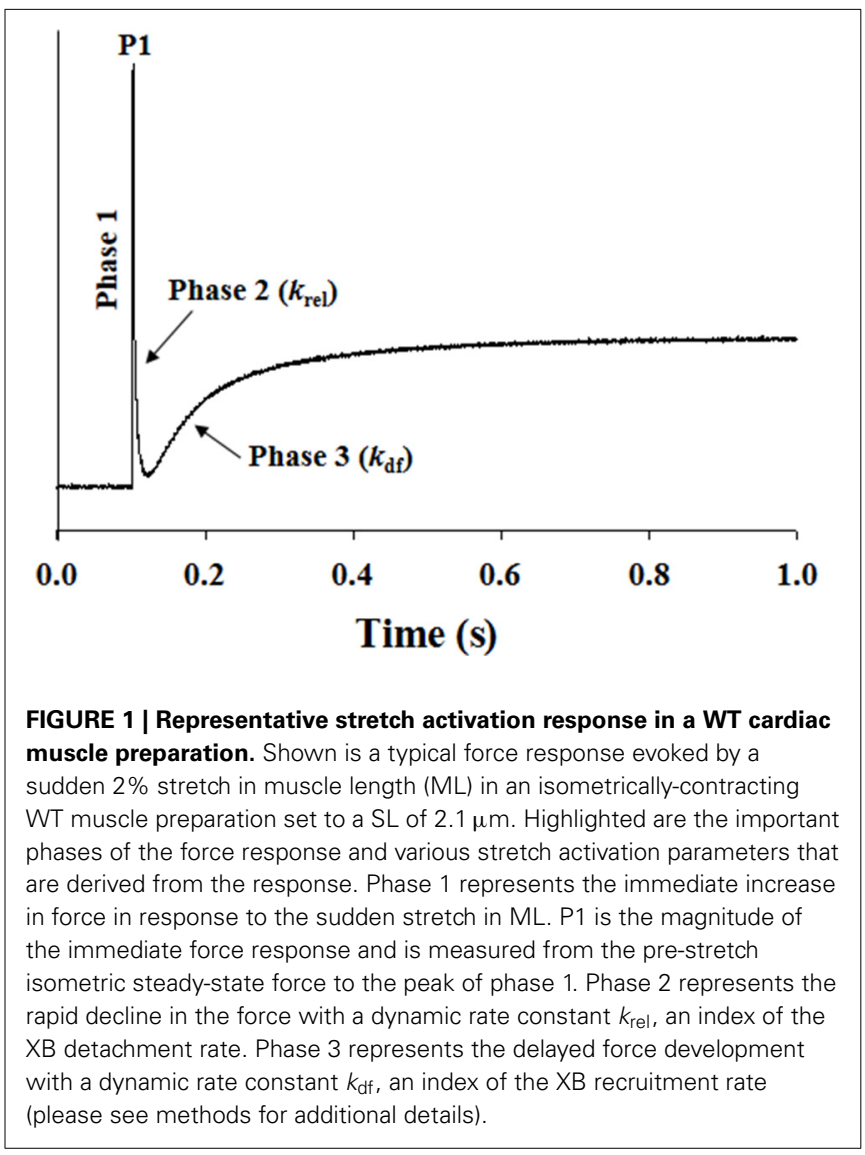


variant (interaction effect). When the interaction effect was significant, it showed that the effects of SL on various contractile parameters were different in the presence or absence of cMyBP-C. When the interaction effect was not significant, we interpreted the main effect due to cMyBP-C variant or SL. Planned multiple pairwise comparisons were made using Fisher's LSD method (Mamidi and Chandra, 2013; Mamidi et al., 2013a,b) to test the effects of cMyBP-C variant or SL on various contractile parameters. Values are reported as mean \pm s.e.m. The criterion for statistical significance was set at $P<0.05$. Asterisks in figures and tables represent statistical significance using post-hoc (Fisher's LSD) comparisons.

\section{RESULTS \\ EFFECT OF ABLATION OF cMYBP-C ON THE EXPRESSION AND PHOSPHORYLATION LEVELS OF SARCOMERIC PROTEINS}

Western blot analysis of WT and KO ventricular samples was done using a primary antibody that detects cMyBP-C protein (Cheng et al., 2013). As predicted, cMyBP-C is present in the WT sample but is completely absent in the KO sample (Figure 2A). SDS gels loaded with ventricular samples from WT and $\mathrm{KO}$ hearts were stained with Coomassie blue or Pro-Q Diamond stain to assess the effects of cMyBP-C KO on sarcomeric protein isoform expression and phosphorylation levels (Figures 2B,C, respectively). As reported in our recent studies (Desjardins et al., 2012; Merkulov et al., 2012) the KO hearts exhibited a slight increase $(16 \pm 3 \%)$ in the level of $\beta$-myosin heavy chain (MHC) expression (data not shown). Consistent with our previous studies (Desjardins et al., 2012; Merkulov et al., 2012), the expression

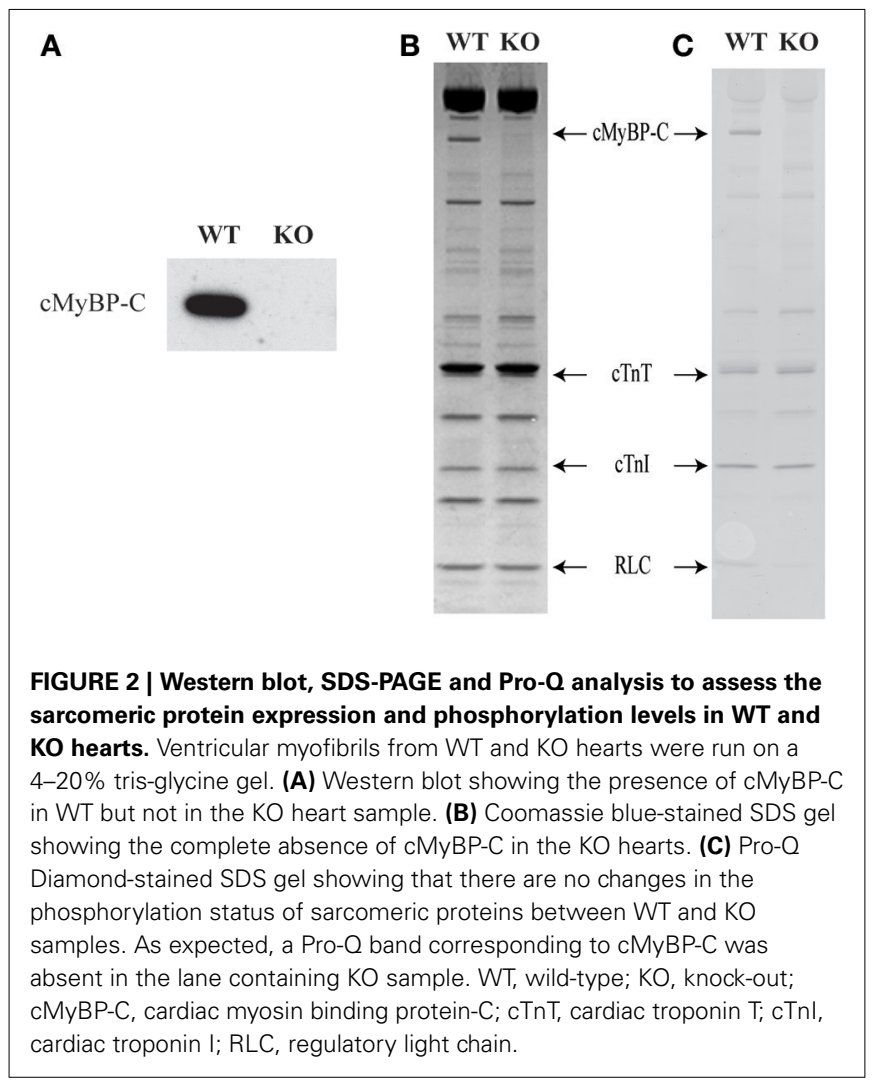

and phosphorylation levels of other regulatory contractile sarcomeric proteins such as cardiac TnT, cardiac TnI, and regulatory light chain were not different between WT and $\mathrm{KO}$ skinned myocardium (Figures 2B,C).

\section{EFFECT OF cMyBP-C ON LENGTH-DEPENDENT CHANGES IN $\mathrm{Ca}^{2+}$-ACTIVATED MAXIMAL FORCE PRODUCTION}

To assess the effect of cMyBP-C on length-dependent changes in thin-filament activation, $\mathrm{Ca}^{2+}$-activated maximal force production (at pCa 4.5) was measured at SL's 1.9 and $2.1 \mu \mathrm{m}$ in WT and KO muscle preparations (values are shown in Table 1). Two-Way ANOVA (see Data analysis under Methods section for details) revealed no significant interaction effect, but revealed a significant main effect $(P<0.005)$ of $\mathrm{SL}$ on $\mathrm{Ca}^{2+}$-activated maximal force production. To probe the determining factor for the significant main effect, subsequent post-hoc tests were carried out. These post-hoc tests using multiple planned pairwise comparisons showed that maximal force production was not significantly different between WT and KO groups at either SL (Table 1). However, maximal force $\left(\mathrm{F}_{\max }\right)$ was significantly decreased by $\sim 34 \%$ and $\sim 38 \%$ at short SL vs. long SL in WT and KO groups, respectively (Table 1). Similar trends were observed regarding the $\mathrm{Ca}^{2+}$-independent forces measured at pCa $9.0\left(\mathrm{~F}_{\min }\right)$ in WT and $\mathrm{KO}$ groups (Table 1). Collectively, our results demonstrate that $\mathrm{CMyBP}-\mathrm{C}$ does not impact the length-dependent changes in $\mathrm{Ca}^{2+}$-activated maximal force and $\mathrm{Ca}^{2+}$-independent force production.

\section{EFFECT OF cMyBP-C ON LENGTH-DEPENDENT CHANGES IN MYOFILAMENT $\mathrm{Ca}^{2+}$ SENSITIVITY $\left(\mathrm{pCa}_{50}\right)$ AND COOPERATIVITY OF FORCE DEVELOPMENT $\left(\boldsymbol{n}_{\mathrm{H}}\right)$}

The effect of cMyBP-C on length-dependent changes in $\mathrm{pCa}_{50}$ was assessed by plotting normalized force values against a range of pCa and constructing force-pCa relationships at SL's 1.9 and $2.1 \mu \mathrm{m}$ in $\mathrm{WT}$ and $\mathrm{KO}$ groups. $\mathrm{pCa}_{50}$, the $\mathrm{pCa}$ required to generate half-maximal force, was estimated by fitting the Hill equation to the force-pCa relationships (Figures 3A,B, Table 1). Two-Way

Table 1 | Steady-state mechanical properties of WT and KO ventricular multicellular preparations.

\begin{tabular}{lcccc}
\hline Group & $\begin{array}{c}\mathrm{F}_{\min } \\
\left(\mathrm{mN} / \mathrm{mm}^{2}\right)\end{array}$ & $\begin{array}{c}\mathrm{F}_{\max } \\
\left(\mathrm{mN} / \mathrm{mm}^{2}\right)\end{array}$ & $n_{\mathrm{H}}$ & $\mathrm{pCa}_{50}$
\end{tabular}

\section{SL $1.9 \mu \mathrm{m}$}

$\begin{array}{lllll}\text { WT } & 0.82 \pm 0.12^{*} & 17.29 \pm 1.98^{*} & 3.41 \pm 0.32 * & 5.71 \pm 0.02^{*} \\ \text { KO } & 0.90 \pm 0.13^{*} & 14.93 \pm 1.56^{*} & 2.30 \pm 0.08^{\dagger} & 5.80 \pm 0.01^{*} \\ \text { SL 2.1 } \boldsymbol{\mu m} & & & & \\ \text { WT } & 2.14 \pm 0.28 & 26.32 \pm 2.93 & 2.47 \pm 0.22 & 5.82 \pm 0.02 \\ \text { KO } & 1.97 \pm 0.25 & 23.98 \pm 2.58 & 2.49 \pm 0.23 & 5.87 \pm 0.02\end{array}$

$F_{\text {min }}: \mathrm{Ca}^{2+}$-independent force measured at pCa 9.0; $F_{\text {max }}$ : maximal $\mathrm{Ca}^{2+}$ activated force measured at $\mathrm{pCa} 4.5 ; n_{H}$ : Hill coefficient of the force-pCa relationship; $p C \mathrm{Ca}_{50}$ : $p C a$ value required for the generation of half-maximal force. Values are expressed as mean \pm s.e.m., from 7 to 17 multicellular preparations and 3 to 5 hearts per each group.

* Significantly different from the corresponding group at SL $2.1 \mu \mathrm{m} ; P<0.05$.

+ Significantly different from the corresponding WT group at SL $1.9 \mu \mathrm{m}, P<0.05$. 


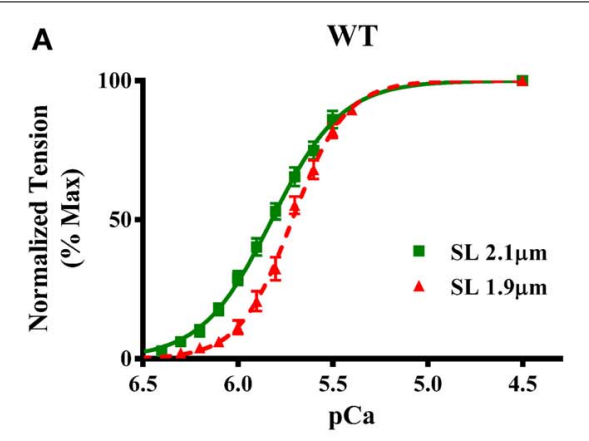

C

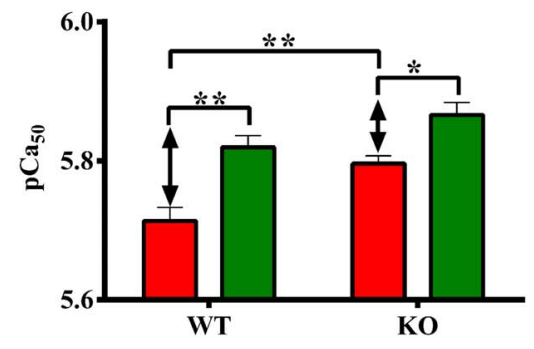

FIGURE 3 | Effect of cMyBP-C on length-dependent changes in myofilament $\mathrm{Ca}^{2+}$ sensitivity $\left(\mathrm{pCa}_{50}\right.$ ) and cooperativity of force production $\left(\boldsymbol{n}_{\mathrm{H}}\right)$. Force-pCa relationships were constructed by plotting normalized forces generated at a range of $\mathrm{pCa}$. The Hill equation was then fitted to force-pCa relationships to estimate $\mathrm{pCa}_{50}$ and $n_{\mathrm{H}}$ values in WT and $\mathrm{KO}$ groups at SL's 1.9 and $2.1 \mu \mathrm{m}$. (A) Effect of cMyBP-C on the force-pCa relationships in WT group at SL's 1.9 and $2.1 \mu \mathrm{m}$. (B) Effect of cMyBP-C on the force-pCa relationships in KO group at SL's 1.9 and $2.1 \mu \mathrm{m}$. (C) Effect of cMyBP-C on pCa 50 in WT and KO groups at SL's 1.9 and $2.1 \mu \mathrm{m}$. (D) Effect of cMyBP-C on $n_{\mathrm{H}}$ in WT and KO groups at SL's 1.9 and $2.1 \mu \mathrm{m}$. Two-Way

ANOVA revealed no significant interaction effect, but revealed significant

D
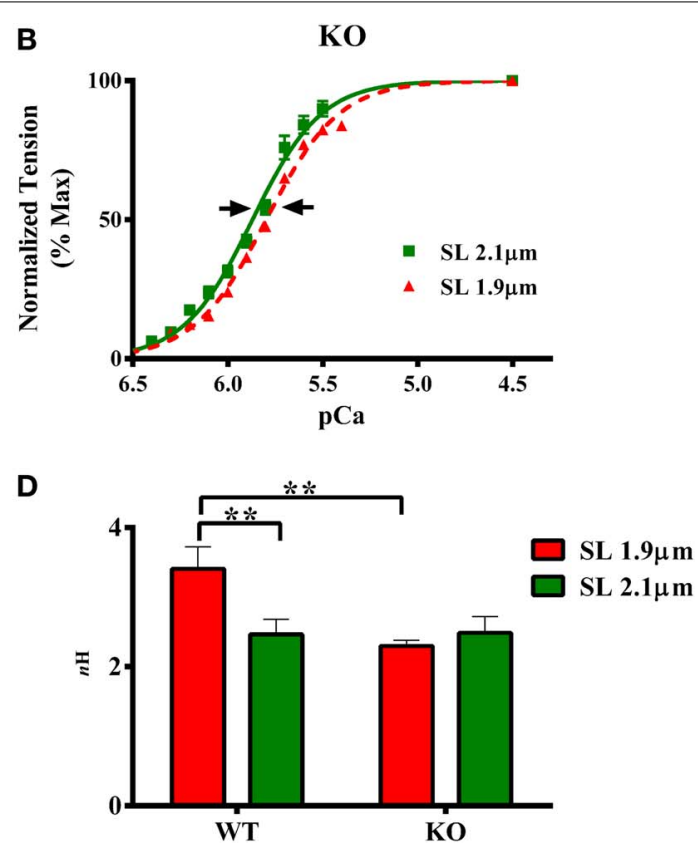

main effects of SL $(P<0.005)$ and cMyBP-C $(P<0.005)$ on $\mathrm{pCa}_{50}$. Subsequent post-hoc tests revealed that $\mathrm{pCa}_{50}$ was significantly higher at $2.1 \mu \mathrm{m}$ as indicated by a leftward shift in the force-pCa relationships in both $\mathrm{WT}$ and $\mathrm{KO}$ groups. Also, the SL-dependent increase in $\mathrm{pCa}_{50}\left(\Delta \mathrm{pCa} \mathrm{a}_{50}\right)$ was attenuated in $\mathrm{KO}$ group (indicated by arrows in $\mathbf{B}, \mathbf{C}$ ). Two-Way ANOVA revealed a significant interaction effect $(P<0.05)$ on $n_{\mathrm{H}}$ suggesting that cMyBP-C influences the effect of SL on $n_{H}$. Subsequent post-hoc tests revealed that $n_{\mathrm{H}}$ significantly increased at SL $1.9 \mu \mathrm{m}$ in WT but not in $\mathrm{KO}$ group. Determinations were made from 7 to 10 multicellular preparations and 3 to 4 hearts per each group. Values are reported as mean \pm s.e.m. $* P<0.05 ; * * P<0.005$.
ANOVA revealed no significant interaction effect, but revealed significant main effects of SL $(P<0.005)$ and cMyBP-C $(P<$ $0.005)$ on $\mathrm{pCa}_{50}$. Subsequent post-hoc tests revealed that the main effect of SL was because of the following: $\mathrm{pCa}_{50}$ significantly increased upon increasing the SL from 1.9 to $2.1 \mu \mathrm{m}$ as indicated by a leftward shift in the force-pCa relationships in both WT and KO groups (Figures 3A,B). The SL-dependent increase in $\mathrm{pCa}_{50}\left(\Delta \mathrm{pCa}_{50}\right)$ was attenuated in $\mathrm{KO}$ group when compared to $\Delta \mathrm{pCa}_{50}$ of WT group (Figure $3 \mathrm{~B}$ ). In WT group $\Delta \mathrm{pCa}_{50}$ was $0.11 \mathrm{pCa}$ units whereas in the KO group $\Delta \mathrm{pCa}_{50}$ was $0.07 \mathrm{pCa}$ units. This attenuation of $\mathrm{pCa}_{50}$ can be attributed to the fact that $\mathrm{KO}$ group exhibited a significantly higher $\mathrm{pCa}_{50}$ at SL $1.9 \mu \mathrm{m}$ compared to WT group (Figure 3C; Table 1), indicating that cardiac thin-filaments are more sensitive to $\mathrm{Ca}^{2+}$ activation at short $\mathrm{SL}$ in the KO group. Collectively, our results demonstrate that cMyBP-C impacts mechanisms that underlie length-dependent increases in myofilament $\mathrm{Ca}^{2+}$ sensitivity.

The effect of cMyBP-C on length-dependent changes in $n_{\mathrm{H}}$ was assessed by fitting Hill's equation to the force-pCa relationships constructed at SL's 1.9 and $2.1 \mu \mathrm{m}$ in WT and $\mathrm{KO}$ groups (Figure 3D; Table 1). Two-Way ANOVA revealed a significant interaction effect $(P<0.05)$ on $n_{\mathrm{H}}$ suggesting that cMyBP-C influenced the effect of SL on $n_{\mathrm{H}}$. Subsequent post-hoc tests revealed that $n_{H}$ significantly increased by $\sim 38 \%$ at SL
$1.9 \mu \mathrm{m}$ in WT group, a result that agrees with earlier studies (Ford et al., 2012; Gollapudi et al., 2012). However, such an increase in $n_{\mathrm{H}}$ at SL $1.9 \mu \mathrm{m}$ was not observed in KO group (Figure 3D)—suggesting that the absence of cMyBP-C impairs length-dependent changes in cooperative mechanisms in the sarcomere.

\section{EFFECT OF cMyBP-C ON LENGTH-DEPENDENT CHANGES IN THE RATE OF FORCE REDEVELOPMENT $\left(K_{t r}\right)$}

$k_{\mathrm{tr}}$ is a measure of XB transition rate from a weakly- to a stronglybound XB state (Brenner and Eisenberg, 1986; Campbell, 1997). We have previously shown that ablation of cMyBP-C accelerates submaximal $k_{\mathrm{tr}}$ at long SL (Stelzer et al., 2006b)—indicating that $\mathrm{KO}$ group exhibited an accelerated rate of XB turnover from weak- to strong-bindings states. We now sought to determine whether such effects are also observed at short SL in the KO group. Therefore, we measured $k_{\mathrm{tr}}$ at 1.9 and $2.1 \mu \mathrm{m}$ to gain insights into the effect of cMyBP-C on length-dependent changes in $k_{\mathrm{tr}}$. TwoWay ANOVA revealed a significant interaction effect $(P<0.005)$ on $k_{\mathrm{tr}}$ suggesting that cMyBP-C influenced the effect of SL on $k_{\mathrm{tr}}$. The cause of the interaction effects was assessed by post-hoc multiple pairwise comparisons which showed that submaximal $k_{\mathrm{tr}}$ was accelerated in KO compared to WT group at long SL (Figure 4; Table 2) as reported earlier (Stelzer et al., 2006b). Furthermore, 


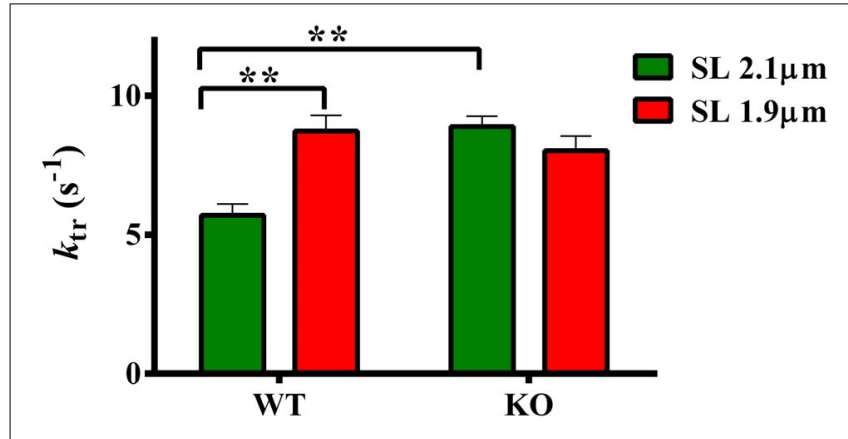

FIGURE 4 | Effect of cMyBP-C on length-dependent changes in the rate of force redevelopment $\left(\boldsymbol{k}_{\mathrm{tr}}\right)$. $k_{\mathrm{tr}}$ was measured at $50 \%$ level of activation in WT and KO groups at SL's 2.1 and $1.9 \mu \mathrm{m}$ using a mechanical slack-restretch protocol (Gresham et al., 2014). Two-Way ANOVA revealed a significant interaction effect $(P<0.005)$ on $k_{\text {tr }}$ and post-hoc tests showed that $k_{\mathrm{tr}}$ significantly accelerated by $\sim 53 \%$ at short SL vs. long SL in WT group. However, such a trend was absent in the KO group. Furthermore, $k_{\mathrm{tr}}$ significantly accelerated by $\sim 56 \%$ in KO vs. WT group at long SL.

Determinations were made from 6 to 13 multicellular preparations and 3 to 4 hearts per each group. Values are reported as mean \pm s.e.m.

** $P<0.005$

Table 2 | Dynamic contractile parameters of WT and KO ventricular multicellular preparations.

\begin{tabular}{lcccc}
\hline Group & $\boldsymbol{k}_{\text {tr }}\left(\mathbf{s}^{-\mathbf{1}}\right)$ & $\boldsymbol{k}_{\text {rel }}\left(\mathbf{s}^{-\mathbf{1}}\right)$ & $\boldsymbol{k}_{\text {df }}\left(\mathbf{s}^{-\mathbf{1}}\right)$ & P1 \\
\hline SL 1.9 $\boldsymbol{\mu \mathbf { m }}$ & & & & \\
WT & $8.74 \pm 0.56^{*}$ & $45.01 \pm 4.06^{*}$ & $12.26 \pm 1.53^{*}$ & $0.535 \pm 0.022^{*}$ \\
KO & $8.03 \pm 0.54$ & $36.96 \pm 2.94$ & $9.64 \pm 0.39$ & $0.543 \pm 0.048$ \\
SL $\mathbf{2 . 1} \boldsymbol{\mu \mathbf { m }}$ & & & & \\
WT & $5.71 \pm 0.40$ & $34.21 \pm 2.12$ & $8.17 \pm 0.52$ & $0.604 \pm 0.016$ \\
KO & $8.90 \pm 0.37^{\dagger}$ & $45.76 \pm 4.01^{\dagger}$ & $11.27 \pm 0.67^{\dagger}$ & $0.528 \pm 0.026^{\dagger}$
\end{tabular}

$k_{t r}$ : rate force redevelopment; $k_{\text {rel }}$ : rate of force decay; $k_{d f}$ : rate of force development; $P_{1}$ : the magnitude of peak force attained following a rapid stretch of muscle length in an isometrically-activated muscle preparation. $k_{\text {rel }}$ and $k_{d f}$ were estimated using a linear transformation of the half time of force decay and force redevelopment. Values are expressed as mean \pm s.e.m., from 6 to 13 multicellular preparations and 3 to 4 hearts per each group.

${ }^{*}$ Significantly different from the corresponding WT group at SL $2.1 \mu \mathrm{m} ; P<0.05$.

${ }^{+}$Significantly different from the corresponding WT group at SL $2.1 \mu \mathrm{m}, P<0.05$.

$k_{\text {tr }}$ was significantly accelerated by $\sim 53 \%$ at short SL compared to long SL in WT group (Figure 4; Table 2). However, an acceleration of $k_{\mathrm{tr}}$ at short SL was absent in KO group (Figure 4) such that differences in $k_{\mathrm{tr}}$ between WT and $\mathrm{KO}$ groups observed at long SL were no longer apparent at short SL. These results indicate that cMyBP-C mediates the length-dependent changes in $\mathrm{XB}$ turnover rate.

\section{EFFECTS OF cMyBP-C ON LENGTH-DEPENDENT CHANGES IN THE RATES OF STRETCH-INDUCED XB RELAXATION $\left(K_{\text {rel }}\right)$ AND XB RECRUITMENT $\left(\boldsymbol{K}_{d f}\right)$}

Our data shows that cMyBP-C affects the length-dependent changes in the $\mathrm{XB}$ turnoverrate, $k_{\mathrm{tr}}$ (Figure 4$)$. Because $k_{\mathrm{tr}}$ is proportional to the sum of $f$ (rate of XB attachment) $+g$ (rate of $\mathrm{XB}$ detachment) according to a two-state $\mathrm{XB}$ model (Brenner,
1988), we sought to determine if the effect of cMyBP-C on lengthdependent changes in $k_{\mathrm{tr}}$ were due to changes in either the rate of $\mathrm{XB}$ detachment or the rate of $\mathrm{XB}$ attachment kinetics, or both. We used stretch activation experiments (described in the methods section) to measure $k_{\text {rel }}$ and $k_{\mathrm{df}}$ which are measures of the rates of XB detachment and XB recruitment, respectively (Cheng et al., 2013; Gresham et al., 2014).

Two-Way ANOVA revealed a significant interaction effect $(P<$ $0.05)$ on $k_{\text {rel }}$ suggesting that $\mathrm{cMyBP}-\mathrm{C}$ influenced the effect of SL on the rate of $\mathrm{XB}$ detachment kinetics. The cause of the interaction effect was evident from the post-hoc multiple pairwise comparisons which revealed that $k_{\text {rel }}$ was significantly accelerated by $\sim 32 \%$ at short SL in WT group but such an acceleration of $k_{\text {rel }}$ at short SL was absent in KO group (Figure 5A; Table 2). Furthermore, in agreement with recent studies (Stelzer et al., 2006a; Merkulov et al., 2012), our data shows that $k_{\text {rel }}$ was significantly accelerated by $\sim 34 \%$ in $\mathrm{KO}$ group compared to WT group at long SL (Figure 5A; Table 2).

Two-Way ANOVA revealed a significant interaction effect $(P<$ $0.005)$ on $k_{\mathrm{df}}$ suggesting that cMyBP-C influenced the effect of SL on the rate of $\mathrm{XB}$ recruitment into the force-bearing state. The cause of the interaction effect was assessed using post-hoc tests which revealed that $k_{\mathrm{df}}$ was significantly accelerated by $\sim 50 \%$ at short SL in WT but such an acceleration of $k_{\mathrm{df}}$ at short SL was absent in KO (Figure 5B; Table 2). Furthermore, in agreement with a previous study (Stelzer et al., 2006a), our data shows that $k_{\mathrm{df}}$ was significantly accelerated by $\sim 38 \%$ in $\mathrm{KO}$ compared to WT at long SL. Thus, our stretch activation data shows that both $k_{\text {rel }}$ and $k_{\mathrm{df}}$ were accelerated at short SL in WT but such trends were absent in the KO (Figures 5A,B). These findings suggest that the absence of acceleration of $k_{\text {tr }}$ at short SL in the KO group (Figure 4) is due to a combined effect of the absence in the accelerations of $k_{\text {rel }}$ and $k_{\mathrm{df}}$ at short SL in KO group (Figure 5). Collectively, our results suggest that $\mathrm{cMyBP}-\mathrm{C}$ modulates length-dependent changes in the kinetics of $\mathrm{XB}$ detachment and attachment in cardiac muscle.

\section{EFFECT OF cMYBP-C ON LENGTH-DEPENDENT CHANGES IN THE MAGNITUDE OF STRETCH-INDUCED INCREASE IN MUSCLE FIBER STIFFNESS (P1)}

Our data shows that the $\mathrm{XB}$ detachment rate $\left(k_{\text {rel }}\right)$ was accelerated at short SL compared to long SL in WT group (Figure 5A). Also, $k_{\text {rel }}$ was accelerated at long SL in KO compared to WT group (Figure 5A). We sought to determine whether such accelerations in $k_{\text {rel }}$ could have arisen from a decrease in the muscle fiber stiffness because changes in $k_{\text {rel }}$ can be correlated with changes in stiffness of XBs (Stelzer et al., 2006c). We imposed a sudden $2 \%$ stretch in muscle length in an isometricallycontracting muscle preparation and measured the magnitude of the elicited instantaneous increase in force (P1 in Figure 1). $\mathrm{P} 1$ is a result of a rapid distortion of the elastic regions of the strongly-bound XBs (Stelzer and Moss, 2006; Ford et al., 2010; Cheng et al., 2013) and is an index of the muscle fiber stiffness because both P1 and muscle fiber stiffness are well correlated to the number of parallel and force-producing XBs that are bound to actin prior to the imposed stretch in muscle length (Campbell et al., 2004; Ford et al., 2010; Cheng et al., 2013). 


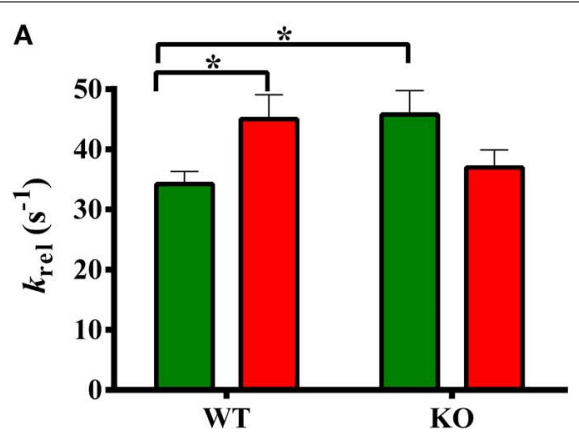

FIGURE 5 | Effect of cMyBP-C on length-dependent changes in the rates of XB detachment $\left(k_{\text {rel }}\right)$ and XB recruitment $\left(k_{\mathrm{df}}\right)$. Isometrically-activated ventricular preparations were subjected to a sudden $2 \%$ stretch in their muscle length and the elicited force responses were used to estimate (A) $k_{\text {rel }}$ and (B) $k_{\mathrm{df}}$ in WT and KO groups at SL's 2.1 and $1.9 \mu \mathrm{m}$ as described in the methods section (Cheng et al., 2013; Gresham et al., 2014). Two-Way ANOVA revealed a significant interaction effect $(P<0.05)$ on $k_{\text {rel }}$ and post-hoc tests showed that $k_{\text {rel }}$ significantly accelerated by $\sim 32 \%$ at short SL vs. long SL in WT
B

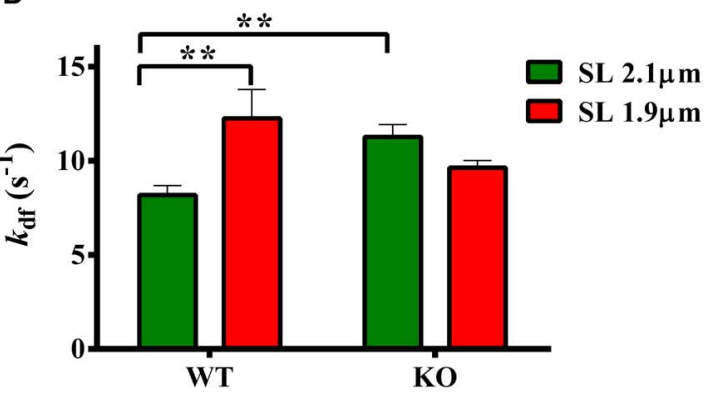

group but such a trend was absent in KO group. $k_{\text {rel }}$ significantly accelerated by $\sim 34 \%$ in KO vs. WT group at long SL (A). Two-Way ANOVA revealed a significant interaction effect $(P<0.005)$ on $k_{\mathrm{df}}$ and post-hoc tests showed that $k_{\mathrm{df}}$ significantly accelerated by $\sim 50 \%$ at short SL vs. long SL in WT group but such a trend was absent in KO group. In addition, $k_{\text {df }}$ significantly accelerated by $\sim 39 \%$ in KO vs. WT group at long SL (B). Determinations were made from 6 to 13

multicellular preparations and 3 to 4 hearts per each group. Values are reported as mean \pm s.e.m. ${ }^{*} P<0.05$; ${ }^{* *} P<0.005$.
Two-Way ANOVA revealed no significant interaction effect and main effects on P1. Post-hoc tests showed that P1 significantly decreased $(P=0.036)$ at short SL compared to long SL in WT group (Figure 6; Table 2). However, such a decrease in P1 at short SL was absent in KO group. Furthermore, P1 was significantly decreased $(P=0.032)$ at long SL in $\mathrm{KO}$ compared to WT (Figure 6; Table 2). These results suggest that a decrease in the muscle fiber stiffness contributed, at least in part, to the acceleration of $k_{\text {rel }}$ observed at short SL compared to long SL in WT, and also at long SL in KO compared to long SL in WT (Figure 5A). Decreased XB stiffness could enhance straininduced rates of $\mathrm{XB}$ detachment by increasing $\mathrm{XB}$ compliance such that XB's detach rapidly (Stelzer et al., 2006c; Cheng et al., 2013)_indicating that changes in P1 can be correlated with changes in $k_{\text {rel }}$. Thus, it is likely that the absence of differences in P1 at long and short SL's in KO group (Figure 6) may have contributed to the lack of differences we observed in $k_{\text {rel }}$ at long and short SL's in KO group (Figure 5A). Collectively, our data suggests that cMyBP-C modulates length-dependent changes in the rate of $\mathrm{XB}$ detachment via its impact on the muscle fiber stiffness.

\section{DISCUSSION}

Given the lack of our understanding regarding cMyBP-C's role in cardiac LDA, we performed a detailed investigation of different aspects of cardiac contractile function both in the presence and absence of cMyBP-C and at SL's 1.9 and $2.1 \mu \mathrm{m}$. Results from our studies demonstrate that length-dependent changes in contractile dynamics are significantly impacted in the absence of cMyBP-C in the cardiac sarcomere. Novel findings from our experiments show an attenuated length-dependent response with respect to steady-state myofilament $\mathrm{Ca}^{2+}$ sensitivity of force generation, and profoundly blunted length-dependent XB cycling dynamics in ventricular preparations isolated from hearts lacking cMyBP-C-suggesting that cMyBP-C is a key modulator of cardiac LDA.

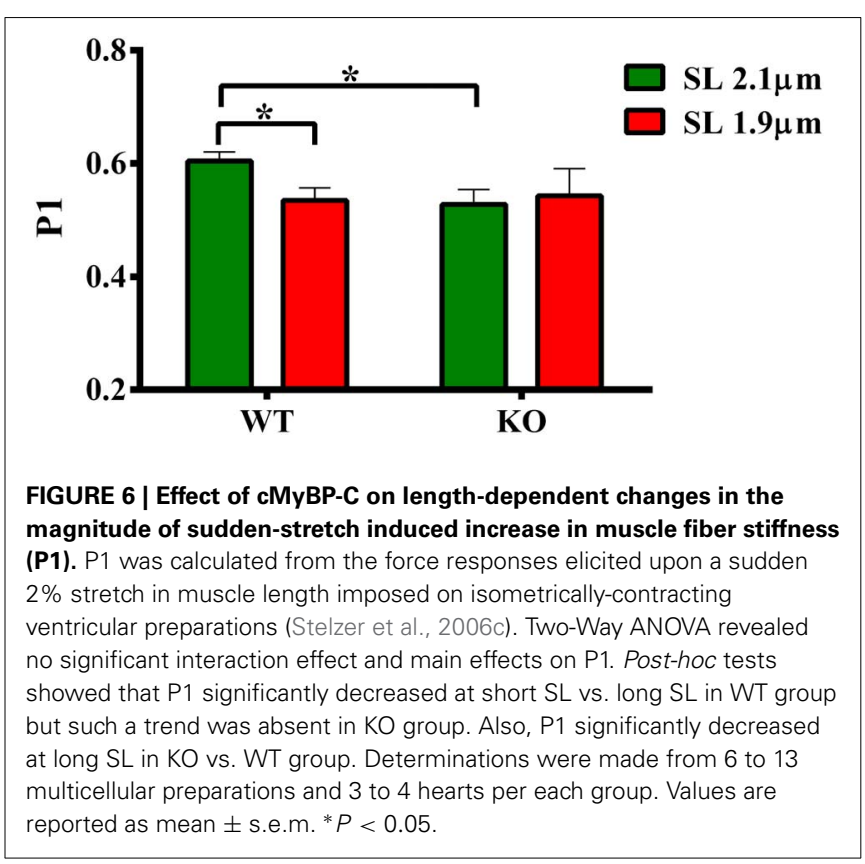

\section{ABLATION OF cMyBP-C ATTENUATES THE LENGTH-DEPENDENT CHANGES IN MYOFILAMENT $\mathrm{Ca}^{2+}$ SENSITIVITY}

An increase in myofilament $\mathrm{Ca}^{2+}$ sensitivity $\left(\mathrm{pCa}_{50}\right)$ upon an increase in SL is a hallmark of LDA (Kentish et al., 1986; Dobesh et al., 2002). The effect of cMyBP-C on LDA is important to study because it is known that LDA is depressed in human hearts expressing cMyBP-C mutations (Van Dijk et al., 2012; Sequeira et al., 2013). Our results show that although the absence of cMyBP-C did not affect maximal force production (Table 1), it did attenuate the SL-mediated increase in $\mathrm{Ca}^{2+}$ sensitivity $\left(\Delta \mathrm{pCa}_{50}\right)$ (Figures 3A-C), a result that agrees with an earlier report (Cazorla et al., 2006). Cazorla et al reported an attenuated $\Delta \mathrm{pCa}_{50}$ in the $\mathrm{KO}$ when compared to the WT myocardium 
$\left(\Delta \mathrm{pCa}_{50}\right.$ of $0.16 \mathrm{pCa}$ units in $\mathrm{KO}$ vs. a $\Delta \mathrm{pCa}_{50}$ of $0.23 \mathrm{pCa}$ units in WT). In this study we found a similar trend, although here the $\triangle \mathrm{pCa}_{50}$ was $0.11 \mathrm{pCa}$ units in WT skinned myocardium whereas it was $0.07 \mathrm{pCa}$ units in $\mathrm{KO}$ skinned myocardium (Figure 3). In our study, the attenuation of $\Delta \mathrm{pCa}_{50}$ was due to higher submaximal force production, as suggested by a higher $\mathrm{pCa}_{50}$, at short $\mathrm{SL}$ in $\mathrm{KO}$ vs. WT group (Figure 3C). These results indicate that the SL-based mechanisms governing myofilament $\mathrm{Ca}^{2+}$ sensitivity are altered in the KO group, and more so at short SL.

In view of the observation that the absence of cMyBP-C shifts the juxtaposition of the myosin heads toward the thin filament (Colson et al., 2007) thereby enhancing the probability of XB interaction, it is likely that the increased force at submaximal $\left[\mathrm{Ca}^{2+}\right]$ at short $\mathrm{SL}$ in $\mathrm{KO}$ group could have arisen from an increased number of XBs interacting with the thin-filament. It is generally accepted that when SL is shortened, the distance between the thick- and thin-filaments increases (Rome, 1968; McDonald and Moss, 1995). It is possible that because cMyBP$\mathrm{C}$ ablation inherently reduces the relative distance between actin and myosin XB's (Colson et al., 2007), the length-dependent increase in acto-myosin distance with decreased SL is diminished in the $\mathrm{KO}$ group, thereby, resulting in greater $\mathrm{XB}$ interaction and increased force production. It is also possible that the observed increase in $\mathrm{Ca}^{2+}$ sensitivity at short SL in the $\mathrm{KO}$ group may be due to an increase in the apparent $\mathrm{Ca}^{2+}$ binding affinity of $\mathrm{TnC}$ mediated by strongly-bound XBs (Pan and Solaro, 1987; Hannon et al., 1992; Moss et al., 2004). In this context, a recent in situ timeresolved FRET study showed that the effects of strongly-bound XBs are transmitted allosterically to the N-terminus of TnC (N$\mathrm{TnC})$ via changes in the interaction between tropomyosin ( $\mathrm{Tm})$ and TnI (Li et al., 2014). The net result of the feedback effect of strongly-bound XBs is to shift the Tm to the open state and also to stabilize the open conformation of the $\mathrm{N}-\mathrm{TnC}$, thereby enhancing the affinity of $\mathrm{TnC}$ for $\mathrm{Ca}^{2+}$ to cause increased force production ( $\mathrm{Li}$ et al., 2014). Thus, enhanced XB interaction at short SL in the absence of cMyBP-C may indirectly increase the $\mathrm{Ca}^{2+}$ sensitivity in the $\mathrm{KO}$ group via a thin filament mediated mechanism.

\section{ABLATION OF cMyBP-C BLUNTS THE LENGTH-DEPENDENT CHANGES IN XB CYCLING KINETICS}

As demonstrated previously (Stelzer et al., 2006b), our present data show that $k_{\mathrm{tr}}$ was accelerated in KO compared to WT group at long SL (Figure 4). Because changes in $k_{\mathrm{tr}}$ indicate a shift in the equilibrium in the transitions between the closed to open states (McKillop and Geeves, 1993) of the thin-filament (Campbell, 1997), our data suggests that in the absence of cMyBP-C the thinfilaments are shifted more toward the open state. To understand the impact of $\mathrm{CMyBP}-\mathrm{C}$ on length-dependent changes in XB transitions/cycling from weak- to strong-binding states, we measured $k_{\mathrm{tr}}$ at short and long SL's. Our data show that $k_{\mathrm{tr}}$ was accelerated at short SL compared to long SL in WT group (Figure 4) indicating the XB cycling is accelerated at short SL. In support of this observation, an earlier study showed that loaded shortening velocity and $k_{\text {tr }}$ were significantly accelerated at short SL compared to long SL in skinned rat cardiac myocytes (Korte and McDonald, 2007). The mechanism for such an increase in $k_{\mathrm{tr}}$ at short SL may arise from the acceleration of $\mathrm{XB}$ cycling kinetics such that there are more XBs working against a constant load because of increased $\mathrm{XB}$ flexibility which allows XBs to radially extend toward the thin-filament at short SL (Korte and McDonald, 2007). Increased flexibility of XBs at short SL may also arise due to decreased stiffness of titin (Granzier and Irving, 1995), a consequence of which is a decreased force exerted by titin on cMyBP-C which can in turn lead to decreased constraint imposed by cMyBP-C on the myosin XBs (Korte and McDonald, 2007). Such increases in $k_{\text {tr }}$ at short SL were also reported by Adhikari et al who attributed the increases in $k_{\mathrm{tr}}$ to an increased XB detachment rate at short SL (Adhikari et al., 2004).

Because $k_{\mathrm{tr}}$ encompasses both the rates of XB attachment $(f)$ and detachment $(g)$ (Brenner and Eisenberg, 1986), we determined if increased $k_{\text {tr }}$ observed at short SL in WT was due to increase in either $f$ or $g$, or both. Using length perturbation experiments (Gresham et al., 2014), we measured the rates of force development $\left(k_{\mathrm{df}}\right)$ and force decay $\left(k_{\mathrm{rel}}\right)$, parameters that are analogous to $f$ and $g$. Our data shows that acceleration of $k_{\text {tr }}$ at short SL in WT group was indeed due to a combination of increases in both $k_{\mathrm{df}}$ and $k_{\text {rel }}$ (Figure 5). Our data also shows that both $k_{\mathrm{df}}$ and $k_{\text {rel }}$ did not increase at short SL in KO skinned myocardium such that the values were not significantly different from those at long SL (Figure 5). A recent study (Tanner et al., 2014) showed that XB detachment rates were accelerated in papillary muscle isolated from $\mathrm{KO}$ hearts compared to $\mathrm{WT}$ hearts but only under a $\beta$-MHC background at very long SL (2.2$3.3 \mu \mathrm{m})$. Under an $\alpha$-MHC background, XB detachment rates displayed a slight non-statistically significant increase in $\mathrm{KO}$ papillary muscles compared to WT papillary muscles, in contrast to the larger accelerations in $\mathrm{XB}$ detachment we observed in $\mathrm{KO}$ multicellular preparations at shorter SL (i.e., $2.1 \mu \mathrm{m}$ ), isolated from hearts expressing predominantly $\alpha$-MHC. Taken together, our data shows that an absence of acceleration in $k_{\text {tr }}$ at short SL in $\mathrm{KO}$ group was due to the absence of accelerations in both $k_{\mathrm{df}}$ and $k_{\text {rel }}$ at short SL (Figure 5). Thus, our study suggests that the mechanisms influencing length-dependent changes in XB transitions between weak- to strong-binding states are blunted in the absence of cMyBP-C.

\section{ABLATION OF cMyBP-C BLUNTS LENGTH-DEPENDENT CHANGES IN MUSCLE FIBER STIFFNESS AND COOPERATIVE MECHANISMS}

To test whether changes in XB detachment (as assessed by $k_{\text {rel }}$, Figure 5) due to CMyBP-C ablation or changes in SL were related to altered $\mathrm{XB}$ compliance and muscle fiber stiffness, we estimated the magnitude of the instantaneous increase in force P1, a parameter that represents the stretch-induced strain of the strongly-bound XBs and an indicator of XB stiffness (Ford et al., 2010; Cheng et al., 2013). Our measurements showed that P1 values were decreased in WT at short SL compared to long SL, and also in $\mathrm{KO}$ at long SL when compared to WT at long SL (Figure 6; Table 2). Because P1 can be correlated to $k_{\text {rel }}$ (Stelzer et al., 2006c; Cheng et al., 2013), our results are consistent with the idea that decreased muscle fiber stiffness contributed to the observed acceleration in the XB detachment. Significantly, our results demonstrate that muscle fiber stiffness decreased at short SL compared to long SL in WT but not in KO group (Figure 6), 
suggesting that the lack of length-dependent changes in $k_{\text {rel }}$ seen in $\mathrm{KO}$ group (Figure 5) may have been related to the lack of length-dependent changes in the muscle fiber stiffness (Figure 6), because muscle fiber stiffness in $\mathrm{KO}$ group is already significantly lower than WT group at long SL.

To test whether changes in XB recruitment, (as assessed by $k_{\mathrm{df}}$, Figure 5) due to cMyBP-C ablation or changes in SL were related to changes in cooperative mechanisms, we estimated the Hill coefficient, $n_{\mathrm{H}}$ from the pCa-tension relationships. Our estimates showed that $n_{\mathrm{H}}$ values were increased in WT at short SL compared to long SL (Figure 3D), a result that is consistent with previous studies (Ford et al., 2012; Gollapudi et al., 2012). This suggests that enhanced cooperative mechanisms may have accelerated the $\mathrm{XB}$ recruitment rate at short SL in WT group. This increase in $n_{\mathrm{H}}$ may be a result of enhanced $\mathrm{Ca}^{2+}$ binding to Tn, near-neighbor interactions among Tn-Tn, XB-Tn, and XB-XB (Razumova et al., 2000; Campbell et al., 2001). Notably, such an increase in $n_{\mathrm{H}}$ at short SL was absent in KO (Figure 3D) which may have likely contributed to the absence of length-dependent changes in $k_{\mathrm{df}}$ in the KO group (Figure 5B). In the context of the KO model, it is likely that depressed cooperative XB-XB (Razumova et al., 2000; Moss et al., 2004), XB-Tn (Razumova et al., 2000; Chandra et al., 2007) and $\mathrm{XB}-\mathrm{Ca}^{2+} / \mathrm{TnC}$ (Li et al., 2014) interactions at short SL may have contributed to the blunting of the increase in $n_{\mathrm{H}}$ with decrease in SL. Therefore, our data shows that length-dependent changes in cooperative mechanisms are depressed when cMyBP-C is absent in the sarcomere.

\section{CONCLUSIONS}

Our study provides evidence to show that cMyBP-C plays a key role in fine-tuning length-dependent cardiac contractile function via its impact on myofilament responsiveness to $\mathrm{Ca}^{2+}, \mathrm{XB}$ cycling kinetics, and muscle fiber stiffness. Taken together, our findings suggest that impaired LDA may contribute to depressed myocardial contractile function in human patients harboring mutations in cMyBP-C that ultimately cause a significant decrease in the amount of $\mathrm{cMyBP}-\mathrm{C}$ expression in the sarcomere.

\section{AUTHOR CONTRIBUTIONS}

Ranganath Mamidi and Julian E. Stelzer contributed to the conception and design of the experiments. Ranganath Mamidi, Kenneth S. Gresham, and Julian E. Stelzer participated in performing the experiments, data acquisition, data analysis, data interpretation, drafting, and revising the manuscript. All authors approved the final version of the manuscript.

\section{ACKNOWLEDGMENTS}

This work was supported by the National Heart, Lung, and Blood Institute Grant (HL-114770-01). We would like to thank Heather Butler, Department of Ophthalmology/Endocrinology at Case Western Reserve University for help with maintaining our mouse colonies.

\section{REFERENCES}

Adhikari, B. B., Regnier, M., Rivera, A. J., Kreutziger, K. L., and Martyn, D. A. (2004). Cardiac length dependence of force and force redevelopment kinetics with altered cross-bridge cycling. Biophys. J. 87, 1784-1794. doi: 10.1529/biophysj.103.039131
Allen, D. G., and Kentish, J. C. (1985). The cellular basis of the length-tension relation in cardiac muscle. J. Mol. Cell. Cardiol. 17, 821-840. doi: 10.1016/S00222828(85)80097-3

Brenner, B. (1988). Effect of Ca2 + on cross-bridge turnover kinetics in skinned single rabbit psoas fibers: implications for regulation of muscle contraction. Proc. Natl. Acad. Sci. U.S.A. 85, 3265-3269. doi: 10.1073/pnas.85.9.3265

Brenner, B., and Eisenberg, E. (1986). Rate of force generation in muscle: correlation with actomyosin ATPase activity in solution. Proc. Natl. Acad. Sci. U.S.A. 83, 3542-3546. doi: 10.1073/pnas.83.10.3542

Butters, C. A., Tobacman, J. B., and Tobacman, L. S. (1997). Cooperative effect of calcium binding to adjacent troponin molecules on the thin filamentmyosin subfragment 1 MgATPase rate. J. Biol. Chem. 272, 13196-13202. doi: $10.1074 /$ jbc.272.20.13196

Campbell, K. (1997). Rate constant of muscle force redevelopment reflects cooperative activation as well as cross-bridge kinetics. Biophys. J. 72, 254-262. doi: 10.1016/S0006-3495(97)78664-8

Campbell, K. B., Chandra, M., Kirkpatrick, R. D., Slinker, B. K., and Hunter, W. C. (2004). Interpreting cardiac muscle force-length dynamics using a novel functional model. Am. J. Physiol. Heart Circ. Physiol. 286, H1535-H1545. doi: 10.1152/ajpheart.01029.2003

Campbell, K. B., Razumova, M. V., Kirkpatrick, R. D., and Slinker, B. K. (2001). Nonlinear myofilament regulatory processes affect frequency-dependent muscle fiber stiffness. Biophys. J. 81, 2278-2296. doi: 10.1016/S0006-3495(01) 75875-4

Campbell, K. S. (2011). Impact of myocyte strain on cardiac myofilament activation. Pflugers Arch. 462, 3-14. doi: 10.1007/s00424-011-0952-3

Campbell, K. S., and Moss, R. L. (2003). SLControl: PC-based data acquisition and analysis for muscle mechanics. Am. J. Physiol. Heart Circ. Physiol. 285, H2857-H2864. doi: 10.1152/ajpheart.00295.2003

Cazorla, O., Szilagyi, S., Vignier, N., Salazar, G., Kramer, E., Vassort, G., et al. (2006). Length and protein kinase a modulations of myocytes in cardiac myosin binding protein C-deficient mice. Cardiovasc. Res. 69, 370-380. doi: 10.1016/j.cardiores.2005.11.009

Chandra, M., Tschirgi, M. L., Ford, S. J., Slinker, B. K., and Campbell, K. B. (2007). Interaction between myosin heavy chain and troponin isoforms modulate cardiac myofiber contractile dynamics. Am. J. Physiol. Regul. Integr. Comp. Physiol. 293, R1595-R1607. doi: 10.1152/ajpregu.00157.2007

Chandra, M., Tschirgi, M. L., Rajapakse, I., and Campbell, K. B. (2006). Troponin T modulates sarcomere length-dependent recruitment of cross-bridges in cardiac muscle. Biophys. J. 90, 2867-2876. doi: 10.1529/biophysj.105.076950

Chen, P. P., Patel, J. R., Rybakova, I. N., Walker, J. W., and Moss, R. L. (2010). Protein kinase A-induced myofilament desensitization to $\mathrm{Ca}(2+)$ as a result of phosphorylation of cardiac myosin-binding protein C. J. Gen. Physiol. 136, 615-627. doi: 10.1085/jgp.201010448

Cheng, Y., Wan, X., McElfresh, T. A., Chen, X., Gresham, K. S., Rosenbaum, D. S., et al. (2013). Impaired contractile function due to decreased cardiac myosin binding protein C content in the sarcomere. Am. J. Physiol. Heart Circ. Physiol. 305, H52-H65. doi: 10.1152/ajpheart.00929.2012

Colson, B. A., Bekyarova, T., Fitzsimons, D. P., Irving, T. C., and Moss, R. L. (2007). Radial displacement of myosin cross-bridges in mouse myocardium due to ablation of myosin binding protein-C. J. Mol. Biol. 367, 36-41. doi: 10.1016/j.jmb.2006.12.063

Coulton, A. T., and Stelzer, J. E. (2012). Cardiac myosin binding protein C and its phosphorylation regulate multiple steps in the cross-bridge cycle of muscle contraction. Biochemistry 51, 3292-3301. doi: 10.1021/bi300085x

Desjardins, C. L., Chen, Y., Coulton, A. T., Hoit, B. D., Yu, X., and Stelzer, J. E. (2012). Cardiac myosin binding protein C insufficiency leads to early onset of mechanical dysfunction. Circ. Cardiovasc. Imaging 5, 127-136. doi: 10.1161/CIRCIMAGING.111.965772

De Tombe, P. P., Mateja, R. D., Tachampa, K., Ait Mou, Y., Farman, G. P., and Irving, T. C. (2010). Myofilament length dependent activation. J. Mol. Cell. Cardiol. 48, 851-858. doi: 10.1016/j.yjmcc.2009.12.017

Dobesh, D. P., Konhilas, J. P., and De Tombe, P. P. (2002). Cooperative activation in cardiac muscle: impact of sarcomere length. Am. J. Physiol. Heart Circ. Physiol. 282, H1055-H1062. doi: 10.1152/ajpheart.00667.2001

Fabiato, A. (1988). Computer programs for calculating total from specified free or free from specified total ionic concentrations in aqueous solutions containing multiple metals and ligands. Meth. Enzymol. 157, 378-417. doi: 10.1016/00766879(88)57093-3 
Farman, G. P., Allen, E. J., Schoenfelt, K. Q., Backx, P. H., and De Tombe, P. P. (2010). The role of thin filament cooperativity in cardiac length-dependent calcium activation. Biophys. J. 99, 2978-2986. doi: 10.1016/j.bpj.2010.09.003

Ford, S. J., Chandra, M., Mamidi, R., Dong, W., and Campbell, K. B. (2010). Model representation of the nonlinear step response in cardiac muscle. J. Gen. Physiol. 136, 159-177. doi: 10.1085/jgp.201010467

Ford, S. J., Mamidi, R., Jimenez, J., Tardiff, J. C., and Chandra, M. (2012). Effects of R92 mutations in mouse cardiac troponin $\mathrm{T}$ are influenced by changes in myosin heavy chain isoform. J. Mol. Cell. Cardiol. 53, 542-551. doi: 10.1016/j.yjmcc.2012.07.018

Fuchs, F., and Smith, S. H. (2001). Calcium, cross-bridges, and the Frank-Starling relationship. News Physiol. Sci. 16, 5-10.

Fukuda, N., Wu, Y., Farman, G., Irving, T. C., and Granzier, H. (2003). Titin isoform variance and length dependence of activation in skinned bovine cardiac muscle. J. Physiol. 553, 147-154. doi: 10.1113/jphysiol.2003.049759

Godt, R. E., and Lindley, B. D. (1982). Influence of temperature upon contractile activation and isometric force production in mechanically skinned muscle fibers of the frog. J. Gen. Physiol. 80, 279-297. doi: 10.1085/jgp.80.2.279

Gollapudi, S. K., Mamidi, R., Mallampalli, S. L., and Chandra, M. (2012). The Nterminal extension of cardiac troponin $\mathrm{T}$ stabilizes the blocked state of cardiac thin filament. Biophys. J. 103, 940-948. doi: 10.1016/j.bpj.2012.07.035

Gordon, A. M., Homsher, E., and Regnier, M. (2000). Regulation of contraction in striated muscle. Physiol. Rev. 80, 853-924.

Granzier, H. L., and Irving, T. C. (1995). Passive tension in cardiac muscle: contribution of collagen, titin, microtubules, and intermediate filaments. Biophys. J. 68, 1027-1044. doi: 10.1016/S0006-3495(95)80278-X

Gresham, K. S., Mamidi, R., and Stelzer, J. E. (2014). The contribution of cardiac myosin binding protein-c Ser282 phosphorylation to the rate of force generation and in vivo cardiac contractility. J. Physiol. 592, 3747-3765. doi: 10.1113/jphysiol.2014.276022

Gulati, J., Sonnenblick, E., and Babu, A. (1991). The role of troponin C in the length dependence of $\mathrm{Ca}(2+)$-sensitive force of mammalian skeletal and cardiac muscles. J. Physiol. 441, 305-324.

Hanft, L. M., Korte, F. S., and McDonald, K. S. (2008). Cardiac function and modulation of sarcomeric function by length. Cardiovasc. Res. 77, 627-636. doi: $10.1093 / \mathrm{cvr} / \mathrm{cvm} 099$

Hannon, J. D., Martyn, D. A., and Gordon, A. M. (1992). Effects of cycling and rigor crossbridges on the conformation of cardiac troponin C. Circ. Res. 71, 984-991. doi: 10.1161/01.RES.71.4.984

Harris, S. P., Bartley, C. R., Hacker, T. A., McDonald, K. S., Douglas, P. S., Greaser, M. L., et al. (2002). Hypertrophic cardiomyopathy in cardiac myosin binding protein-C knockout mice. Circ. Res. 90, 594-601. doi: 10.1161/01.RES.0000012222.70819.64

Kentish, J. C., Ter Keurs, H. E., Ricciardi, L., Bucx, J. J., and Noble, M. I. (1986). Comparison between the sarcomere length-force relations of intact and skinned trabeculae from rat right ventricle. Influence of calcium concentrations on these relations. Circ. Res. 58, 755-768. doi: 10.1161/01.RES. 58.6.755

Konhilas, J. P., Irving, T. C., and De Tombe, P. P. (2002). Frank-Starling law of the heart and the cellular mechanisms of length-dependent activation. Pflugers Arch. 445, 305-310. doi: 10.1007/s00424-002-0902-1

Konhilas, J. P., Irving, T. C., Wolska, B. M., Jweied, E. E., Martin, A. F., Solaro, R. J., et al. (2003). Troponin I in the murine myocardium: influence on lengthdependent activation and interfilament spacing. J. Physiol. 547, 951-961. doi: 10.1113/jphysiol.2002.038117

Korte, F. S., and McDonald, K. S. (2007). Sarcomere length dependence of rat skinned cardiac myocyte mechanical properties: dependence on myosin heavy chain. J. Physiol. 581, 725-739. doi: 10.1113/jphysiol.2007. 128199

Li, K. L., Rieck, D., Solaro, R. J., and Dong, W. (2014). In situ time-resolved FRET reveals effects of sarcomere length on cardiac thin-filament activation. Biophys. J. 107, 682-693. doi: 10.1016/j.bpj.2014.05.044

Mamidi, R., and Chandra, M. (2013). Divergent effects of alpha- and beta-myosin heavy chain isoforms on the $\mathrm{N}$ terminus of rat cardiac troponin T. J. Gen. Physiol. 142, 413-423. doi: 10.1085/jgp.201310971

Mamidi, R., Mallampalli, S. L., Wieczorek, D. F., and Chandra, M. (2013a). Identification of two new regions in the $\mathrm{N}$-terminus of cardiac troponin $\mathrm{T}$ that have divergent effects on cardiac contractile function. J. Physiol. 591, 1217-1234. doi: 10.1113/jphysiol.2012.243394
Mamidi, R., Muthuchamy, M., and Chandra, M. (2013b). Instability in the central region of tropomyosin modulates the function of its overlapping ends. Biophys. J. 105, 2104-2113. doi: 10.1016/j.bpj.2013.09.026

McDonald, K. S., and Moss, R. L. (1995). Osmotic compression of single cardiac myocytes eliminates the reduction in $\mathrm{Ca} 2+$ sensitivity of tension at short sarcomere length. Circ. Res. 77, 199-205. doi: 10.1161/01.RES.77.1.199

McKillop, D. F., and Geeves, M. A. (1993). Regulation of the interaction between actin and myosin subfragment 1: evidence for three states of the thin filament. Biophys. J. 65, 693-701. doi: 10.1016/S0006-3495(93)81110-X

Merkulov, S., Chen, X., Chandler, M. P., and Stelzer, J. E. (2012). In vivo cardiac myosin binding protein $\mathrm{C}$ gene transfer rescues myofilament contractile dysfunction in cardiac myosin binding protein $\mathrm{C}$ null mice. Circ. Heart Fail. 5, 635-644. doi: 10.1161/CIRCHEARTFAILURE.112.968941

Michael, J. J., Gollapudi, S. K., Ford, S. J., Kazmierczak, K., Szczesna-Cordary, D., and Chandra, M. (2013). Deletion of 1-43 amino acids in cardiac myosin essential light chain blunts length dependency of $\mathrm{Ca}(2+)$ sensitivity and cross-bridge detachment kinetics. Am. J. Physiol. Heart Circ. Physiol. 304, H253-H259. doi: 10.1152/ajpheart.00572.2012

Moss, R. L., Razumova, M., and Fitzsimons, D. P. (2004). Myosin crossbridge activation of cardiac thin filaments: implications for myocardial function in health and disease. Circ. Res. 94, 1290-1300. doi: 10.1161/01.RES.0000127125.61647.4F

Mun, J. Y., Previs, M. J., Yu, H. Y., Gulick, J., Tobacman, L. S., Beck Previs, S., et al. (2014). Myosin-binding protein $\mathrm{C}$ displaces tropomyosin to activate cardiac thin filaments and governs their speed by an independent mechanism. Proc. Natl. Acad. Sci. U.S.A. 111, 2170-2175. doi: 10.1073/pnas.1316001111

Palmer, B. M., Sadayappan, S., Wang, Y., Weith, A. E., Previs, M. J., Bekyarova, T., et al. (2011). Roles for cardiac MyBP-C in maintaining myofilament lattice rigidity and prolonging myosin cross-bridge lifetime. Biophys. J. 101, 1661-1669. doi: 10.1016/j.bpj.2011.08.047

Pan, B. S., and Solaro, R. J. (1987). Calcium-binding properties of troponin C in detergent-skinned heart muscle fibers. J. Biol. Chem. 262, 7839-7849.

Pollack, G. H., and Huntsman, L. L. (1974). Sarcomere length-active force relations in living mammalian cardiac muscle. Am. J. Physiol. 227, 383-389.

Previs, M. J., Beck Previs, S., Gulick, J., Robbins, J., and Warshaw, D. M. (2012). Molecular mechanics of cardiac myosin-binding protein $\mathrm{C}$ in native thick filaments. Science 337, 1215-1218. doi: 10.1126/science.1223602

Razumova, M. V., Bukatina, A. E., and Campbell, K. B. (2000). Different myofilament nearest-neighbor interactions have distinctive effects on contractile behavior. Biophys. J. 78, 3120-3137. doi: 10.1016/S0006-3495(00)76849-4

Regnier, M., Martin, H., Barsotti, R. J., Rivera, A. J., Martyn, D. A., and Clemmens, E. (2004). Cross-bridge versus thin filament contributions to the level and rate of force development in cardiac muscle. Biophys. J. 87, 1815-1824. doi: 10.1529/biophysj.103.039123

Rodriguez, E. K., Hunter, W. C., Royce, M. J., Leppo, M. K., Douglas, A. S., and Weisman, H. F. (1992). A method to reconstruct myocardial sarcomere lengths and orientations at transmural sites in beating canine hearts. Am. J. Physiol. 263, H293-H306.

Rome, E. (1968). X-ray diffraction studies of the filament lattice of striated muscle in various bathing media. J. Mol. Biol. 37, 331-344. doi: 10.1016/00222836(68)90272-6

Sadayappan, S., and De Tombe, P. P. (2012). Cardiac myosin binding proteinC: redefining its structure and function. Biophys. Rev. 4, 93-106. doi: 10.1007/s12551-012-0067-x

Sequeira, V., Wijnker, P. J., Nijenkamp, L. L., Kuster, D. W., Najafi, A., WitjasPaalberends, E. R., et al. (2013). Perturbed length-dependent activation in human hypertrophic cardiomyopathy with missense sarcomeric gene mutations. Circ. Res. 112, 1491-1505. doi: 10.1161/CIRCRESAHA.111.300436

Shaffer, J. F., Kensler, R. W., and Harris, S. P. (2009). The myosin-binding protein $\mathrm{C}$ motif binds to F-actin in a phosphorylation-sensitive manner. J. Biol. Chem. 284, 12318-12327. doi: 10.1074/jbc.M808850200

Squire, J. M., Luther, P. K., and Knupp, C. (2003). Structural evidence for the interaction of $\mathrm{C}$-protein $(\mathrm{MyBP}-\mathrm{C})$ with actin and sequence identification of a possible actin-binding domain. J. Mol. Biol. 331, 713-724. doi: 10.1016/S00222836(03)00781-2

Stelzer, J. E., Dunning, S. B., and Moss, R. L. (2006a). Ablation of cardiac myosin-binding protein-C accelerates stretch activation in murine skinned myocardium. Circ. Res. 98, 1212-1218. doi: 10.1161/01.RES.0000219863. 94390.ce 
Stelzer, J. E., Fitzsimons, D. P., and Moss, R. L. (2006b). Ablation of myosin-binding protein-C accelerates force development in mouse myocardium. Biophys. J. 90 4119-4127. doi: 10.1529/biophysj.105.078147

Stelzer, J. E., Larsson, L., Fitzsimons, D. P., and Moss, R. L. (2006c). Activation dependence of stretch activation in mouse skinned myocardium: implications for ventricular function. J. Gen. Physiol. 127, 95-107. doi: 10.1085/jgp.200509432

Stelzer, J. E., and Moss, R. L. (2006). Contributions of stretch activation to lengthdependent contraction in murine myocardium. J. Gen. Physiol. 128, 461-471. doi: 10.1085/jgp.200609634

Stelzer, J. E., Patel, J. R., and Moss, R. L. (2006d). Acceleration of stretch activation in murine myocardium due to phosphorylation of myosin regulatory light chain. J. Gen. Physiol. 128, 261-272. doi: 10.1085/jgp. 200609547

Tachampa, K., Wang, H., Farman, G. P., and De Tombe, P. P. (2007). Cardiac troponin I threonine 144: role in myofilament length dependent activation. Circ. Res. 101, 1081-1083. doi: 10.1161/CIRCRESAHA.107. 165258

Tanner, B. C., Wang, Y., Robbins, J., and Palmer, B. M. (2014). Kinetics of cardiac myosin isoforms in mouse myocardium are affected differently by presence of myosin binding protein-C. J. Muscle Res. Cell Motil. doi: 10.1007/s10974-0149390-0. [Epub ahead of print].
Van Dijk, S. J., Paalberends, E. R., Najafi, A., Michels, M., Sadayappan, S., Carrier, L., et al. (2012). Contractile dysfunction irrespective of the mutant protein in human hypertrophic cardiomyopathy with normal systolic function. Circ. Heart Fail. 5, 36-46. doi: 10.1161/CIRCHEARTFAILURE.111.963702

Conflict of Interest Statement: The authors declare that the research was conducted in the absence of any commercial or financial relationships that could be construed as a potential conflict of interest.

Received: 20 October 2014; accepted: 10 November 2014; published online: 02 December 2014

Citation: Mamidi R, Gresham KS and Stelzer JE (2014) Length-dependent changes in contractile dynamics are blunted due to cardiac myosin binding protein-C ablation. Front. Physiol. 5:461. doi: 10.3389/fphys.2014.00461

This article was submitted to Striated Muscle Physiology, a section of the journal Frontiers in Physiology.

Copyright (c) 2014 Mamidi, Gresham and Stelzer. This is an open-access article distributed under the terms of the Creative Commons Attribution License (CC BY). The use, distribution or reproduction in other forums is permitted, provided the original author(s) or licensor are credited and that the original publication in this journal is cited, in accordance with accepted academic practice. No use, distribution or reproduction is permitted which does not comply with these terms. 